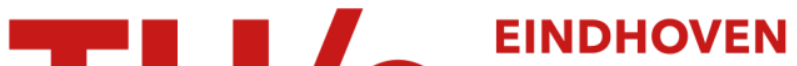 UNIVERSITY OF TECHNOLOGY
}

\section{Transient stability of distributed generation in MV-ring networks}

Citation for published version (APA):

Coster, E. J., Myrzik, J. M. A., \& Kling, W. L. (2008). Transient stability of distributed generation in MV-ring networks. In T\&D. IEEE/PES Transmission and Distribution Conference and Exposition, 2008, 21-24 April 2008, Chicago, Illinois (pp. 1-7). Institute of Electrical and Electronics Engineers. https://doi.org/10.1109/TDC.2008.4517144

DOI:

10.1109/TDC.2008.4517144

Document status and date:

Published: 01/01/2008

\section{Document Version:}

Publisher's PDF, also known as Version of Record (includes final page, issue and volume numbers)

\section{Please check the document version of this publication:}

- A submitted manuscript is the version of the article upon submission and before peer-review. There can be important differences between the submitted version and the official published version of record. People interested in the research are advised to contact the author for the final version of the publication, or visit the $\mathrm{DOI}$ to the publisher's website.

- The final author version and the galley proof are versions of the publication after peer review.

- The final published version features the final layout of the paper including the volume, issue and page numbers.

Link to publication

\section{General rights}

Copyright and moral rights for the publications made accessible in the public portal are retained by the authors and/or other copyright owners and it is a condition of accessing publications that users recognise and abide by the legal requirements associated with these rights.

- Users may download and print one copy of any publication from the public portal for the purpose of private study or research.

- You may not further distribute the material or use it for any profit-making activity or commercial gain

- You may freely distribute the URL identifying the publication in the public portal.

If the publication is distributed under the terms of Article $25 \mathrm{fa}$ of the Dutch Copyright Act, indicated by the "Taverne" license above, please follow below link for the End User Agreement:

www.tue.nl/taverne

Take down policy

If you believe that this document breaches copyright please contact us at:

openaccess@tue.nl

providing details and we will investigate your claim. 


\title{
Transient Stability of Distributed Generation in MV-Ring Networks
}

\author{
E.J. Coster, Student Member, IEEE, J.M.A. Myrzik, and W.L. Kling, Member, IEEE
}

\begin{abstract}
Due to the increase of distributed generation (DG) in the future it can become important to keep DG connected to the grid in order to maintain balance between consumed and generated electrical power. Keeping DG-units connected to the grid during a disturbance, the dynamic behavior of the DG-units becomes important. To guarantee after fault clearing stable operation of the DG-units, the protection scheme and settings have to be changed. In this paper conventional protection schemes of MVRing Networks are discussed as well as the additional measures that have to be taken to protect a MV-Ring Network including DG properly. It is found that it is not possible to find a proper relay setting to protect the MV-Ring Network in such a way that the fault clearing process is fast enough to maintain stability of the DG-units. In the paper it is demonstrated that the fault clearing process can be sped up by adding communication to the protection scheme.
\end{abstract}

Index Terms- Transient stability, Protection, Combined Heat and Power, Medium Voltage Grid

\section{INTRODUCTION}

$\mathbf{N}$ OWADAYS a part of the distribution grid already contains distributed generation units (DG-units). It is to be expected that the amount of DG-units will increase in the near future. Some long term perspectives for the integration of DG predict an increase in small Combined Heat and Power plants (CHP-plants) followed by wind and biomass plants [11]. In certain parts of the Netherlands this growth has already started due to the development of greenhouse areas. In each greenhouse a small CHP-plant is installed which consists of a synchronous generator and a natural gas engine as prime mover. Besides electricity the CHP-plant also produces heat and $\mathrm{CO}_{2}$ which is used in the greenhouse and the electricity is sold to the market.

Most of the MV-grids have a simple radial topology which allow simple protection schemes. Due to the transition from passive $\mathrm{MV}$-grids to active $\mathrm{MV}$-grids, the direction of the power flow and short

E.J. Coster is with ENECO NetBeheer, Rotterdam, the Netherlands (email:e.j.coster@netbeheer.eneco.nl)

J.M.A. Myrzik, and W.L. Kling are with the University of Technology Eindhoven, Eindhoven, the Netherlands circuit currents change. These changes can affect proper operation of the protection schemes. According to various international standards as well as national grid codes, during a disturbance DG-units have to be disconnected immediately [1]. In this way DG units do not contribute to the continuous short circuit current and proper operation of the protection system is guaranteed. In future with a larger amount of DG it will become important to keep the generators connected to the grid in order to maintain balance between generation and load [4], [7].

\section{DEFINITION OF THE PROBLEM}

At this moment the requirement of immediate disconnection is met by equipping the CHP-plant with an under-voltage protection relay. During a disturbance in the MV-grid the voltage drops below the threshold value and after a certain time the CHP-plants are disconnected. The current settings of the under-voltage protection are 0.8 p.u. $-200 \mathrm{~ms}$. Due to these settings the CHP-plants also disconnect at voltage dips caused by disturbances in the HV-grid. However, these voltage dips cover a larger area than voltage dips caused by disturbances in the MV-grid and can lead to massive disconnection of CHP-plants. To prevent massive disconnection the settings of the under-voltage protection have to be changed in such a way that the CHP-plants do not disconnect due to voltage dips in the HV-grid and are properly protected against severe voltage dips in the MV-grid.

Changing the settings of the under-voltage protection also means that the over-current protection have to be changed. Prevention of instability of the CHP-plants asks for a fast fault clearing process. In [10] it is stated that the fault clearing process of MV-feeders is to slow to guarantee stability for the remaining DG-units connected to the feeder. In this paper the effect of closed ring operation of a MVgrid including DG-units on protection as well as transient behavior of the DG-units is studied. The goal is to speed up the fault clearing process in 
such a way that the remaining generators maintain stability.

\section{Motivation FOR CLOSED MV-RING NETWORKS}

Normally a distribution grid is build of meshed or ring-connected feeders, however most of the time the grid is operated radially. This way of operation allows a simple but effective protection scheme based on over-current protection relays. Changing the operation of radial feeders to closed ring feeders offers the following benefits [3], [8]:

- reducing power losses

- reducing voltage rise/drops

- increased stability of DG-units

- increasing the integration capacity of DGunits

The latter is especially beneficial in weak distribution systems.

A major disadvantage is that the protection scheme becomes more complicated. However, it is to be expected that with the aid of a proper protection scheme the availability of the DG-units can be increased.

\section{TEST GRID}

In the Netherlands local authorities have designate areas where horticultural activities can be developed. In these areas greenhouses are build including a CHP-plant with a capacity of $2.4 \mathrm{MW}$. In most cases the capacity of the current MVgrid is not sufficient and reinforcements have to be done by building new substations and cable connections. The total amount of generated power in these areas can be up to $100 \mathrm{MW}$ which means that the local substation have to be connected to the transmission grid. The applied MV-grid is build of MV-ring structures including a grid opening. Each greenhouse is connected by a Ring Main Unit (RMU) and at the most six greenhouses are connected per MV-feeder. In figure 1 a schematic overview of the MV-grid in the greenhouse area is depicted. The distance of the substation to the first RMU is approximately a few kilometers while the distance between two adjacent greenhouses is only a few hundred meters.

In this paper a single MV-ring shaped feeder including four CHP-plants is considered which is shown in figure 2. In the simulations the grid is operated with a closed grid opening. The nominal voltage of the MV-grid is $20 \mathrm{kV}$ however, the CHPplants are operated at $10 \mathrm{kV}$ and are connected to the MV-grid via a transformer.

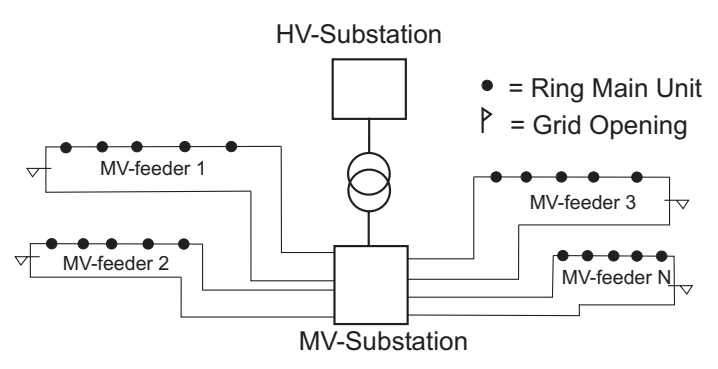

Fig. 1. Schematic overview of a MV-grid in a greenhouse area

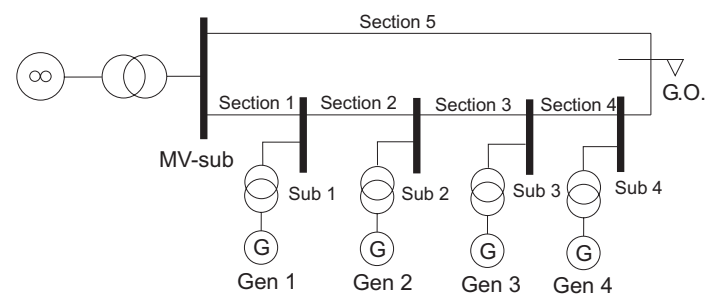

Fig. 2. Test grid including DG-units

To the test grid 4 DG-units with a rating of 3 MVA, p.f. 0.8 are connected. All units are operated with unity power factor. For the cable connections XLPE 3x1x630 $\mathrm{mm}^{2} \mathrm{Al}$ cable is used.

\section{PRotection OF MV-GRIDS}

As mentioned earlier due to the simple topology of MV-grids the applied protection scheme is also simple. Most MV-grids are operated radial which allows protection with a simple definite or inverse over-current protection. In the Netherlands in most cases definite over-current protection is applied. Detailed description of protection schemes of a radial feeder can be found in [2].

\section{A. Classical Protection scheme of MV-ring net- works}

The protection of a MV-ring network is more complicated. The protection of these grids will be explained with the aid of figure 3 . In this figure a MV-feeder including protection relays and two sources at each side of the feeder is depicted. The short circuit behavior of this feeder is equivalent with the closed ring MV-grid. In case of a disturbance both sources contribute to the short circuit current. To protect the feeder properly the protection relays have to be directional sensitive. The arrows in figure 3 show the direction of operation.

Due to the directional element the relay is only reacting on a short circuit current contribution of source 1 or source 2 . This means for setting the 


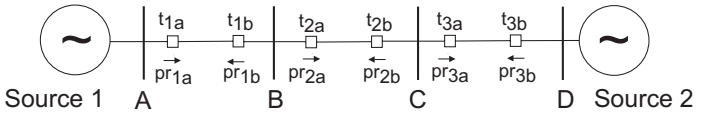

Fig. 3. Directional protection scheme

protection relays $p r_{1 a}, p r_{2 a}$ and $p r_{3 a}$ only source 1 and for $p r_{1 b}, p r_{2 b}$ and $p r_{3 b}$ only source 2 have to be considered. To guarantee selective protection $t_{1 a}>t_{2 a}>t_{3 a}$ and $t_{3 b}>t_{2 b}>t_{1 b}$. This is shown in the grading diagram in figure 4 .

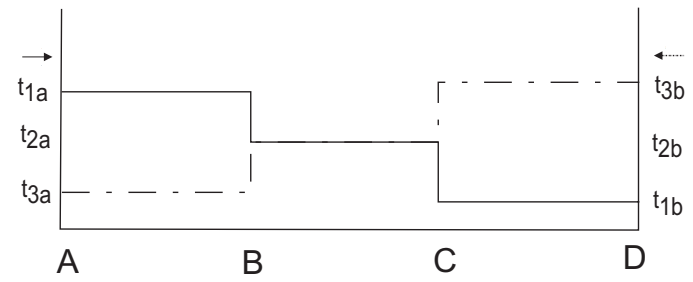

Fig. 4. Grading of a directional protection scheme

For time grading traditional figures of $300 \mathrm{~ms}$ to $500 \mathrm{~ms}$ are applied. These figures are based on the operation time of electromechanical relays. When applying modern digital relays the time grading can be reduced to $125 \mathrm{~ms}$. In this paper traditional grading means a time grading of $300 \mathrm{~ms}$ and reduced grading means $125 \mathrm{~ms}$.

\section{B. Advanced Protection scheme of MV-ring net- works}

Another way of protecting MV-ring networks is adding communication to the protection scheme. With the aid of a communication channel upstream blocking protection schemes can be applied. The upstream blocking principle is based on the classical protection scheme described in section $\mathrm{V}-\mathrm{A}$. To this protection scheme between each upstream protection relay communication channels are installed. A schematic overview of the test grid of figure 2 including the protection scheme is shown in figure 5.

In this figure the dotted line shows the communication channel between the relays and the arrow is pointed to the relay which is blocked by the next downstream directional relay. The principle of the protection scheme will be explained by assuming a three phase fault at feeder 2 . The relay settings are in such a way that during a fault all the involved relays senses the fault current. In this case the relays $p r_{1 a}$ and $p r_{2 a}$ as well as $p r_{2 b}, p r_{3 b}, p r_{4 b}$ and $p r_{5 b}$ will sense the fault current. Relay $p r_{2 a}$ will

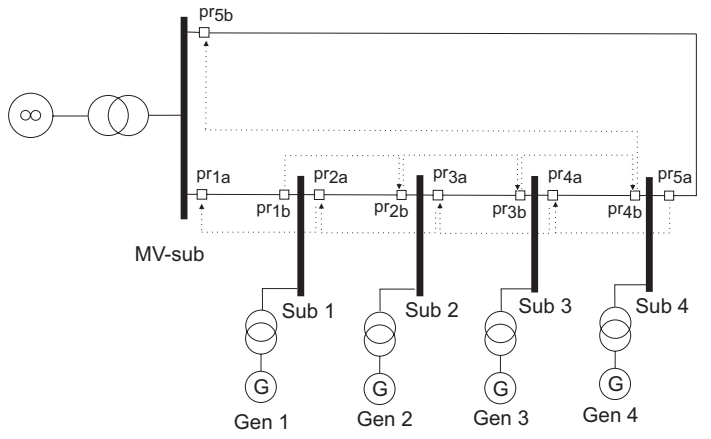

Fig. 5. Test grid including upstream blocking directional protection scheme

send a blocking signal to relay $p r_{1 a}$ and by this blocking signal relay $p r_{1 a}$ is prevented to clear the fault. At the other side of feeder 2 relay $p r_{2 b}$ also senses the fault current which results in a blocking signal and prevention of fault clearing by relay $p r_{3 b}$. The same principle holds for relay $p r_{3 b}, p r_{4 b}$ and $p r_{5 b}$. Due to all the blocking signals only relay $p r_{2 a}$ and $p r_{2 b}$ are activated and clears the fault. As a back-up protection there are two over-current relays added in the main substation. Applying this protection scheme to MV-ring networks can lead to fast fault clearing and can guarantee stable operation of DG-units.

\section{MOdELING OF THE PROTECTION RELAYS}

To simulate the discussed protection schemes, it is necessary to model the protection relays. The relays are modeled in DIgSILENT's software package PowerFactory. The directional relay is based on a generic directional relay scheme which comprises a measurement block, a directional block and an instantaneous over-current block. The complete block diagram is depicted in figure 6 .

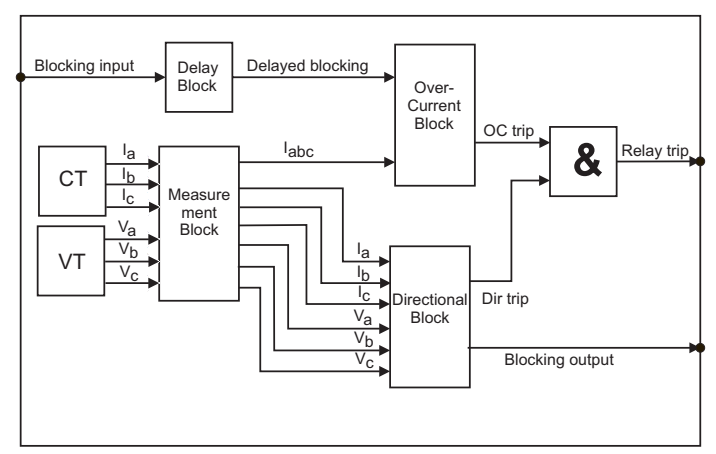

Fig. 6. Block scheme of the directional relay model

The measurement block provide the over-current block and the directional block of the correct values 
of the voltages and the currents obtained from the current and voltage transformers. The over-current block detects an over-current and trips when for a certain time a threshold value is exceeded. The time and threshold value are given by the relay settings. The over-current block also consist a blocking input which is used for the upstream blocking protection scheme. When a blocking signal is present a trip signal of the over-current block is suppressed. To study the delay of the communication system a delay block is added to the blocking input of the over-current block.

The directional block detects whether the direction of the energy belonging to the fault current is in forward or reverse direction. If the direction is forward an active forward signal is generated and if the direction is reverse an active reverse signal is generated. The forward signal of the directional block is used to generate the blocking signal for the first upstream relay. The blocking signal is active when the directional block detects the fault in a forward direction.

The directional block also contains a trip signal which is dependent of the relay settings. If the relay is set in forward direction the trip signal is generated when the fault is in forward direction. If the fault is in reverse direction the directional block will not generate a trip signal. Both the trip signals of the directional block and the over-current block are combined in a logical AND-function. This AND-function generates the trip signal which trips the circuit breaker.

\section{Stability of Synchronous Machines}

Normally the synchronous machine connected to the distribution grid runs at synchronous speed of the grid. The behavior of DG-units during a disturbance can be described with the well known swing equation [9].

$$
\frac{2 H}{\omega_{s}} \frac{d^{2} \delta}{d t}=P_{m}-P_{e}
$$

With the electrical delivered power to the grid:

$$
P_{e}=\frac{E \cdot U}{X} \sin \delta
$$

With the aid of the equal area criterion, the critical clearing time (CCT) can be derived:

$$
t_{c r}=\sqrt{\frac{4 H\left(\delta_{c r}-\delta_{0}\right)}{\omega_{s} P_{m}}}
$$

A detailed description and derivation can be found in [9]. In equation (1)-(3) $\mathrm{H}$ is the inertia constant, $\mathrm{P}_{\mathrm{m}}$ the mechanical power, $\omega_{\mathrm{s}}$ the synchronous rotor speed, $\delta_{c r}$ the critical clearing angle and $\delta_{0}$ the initial rotor angle. The mentioned equations are principally only valid for two machine systems. However, the CCT of the DG-units determined by simulation shows a great similarity with the values calculated with (3). The CCT of the DG-units considered in this paper is $230 \mathrm{~ms}$ and this value is in agreement with values found in literature [7].

\section{Simulations}

To investigate the behavior of the DG-units the test grid including the discussed protection schemes are modeled in DIgSILENT's software package PowerFactory. With the aid of this model three case studies are carried out, such as:

1) Case C1 Directional protection scheme with traditional time grading

2) Case C2 Directional protection scheme with reduced time grading

3) Case C3 Directional protection scheme with upstream blocking

The aim of the study cases is to investigate the effect of the protection schemes on the transient behavior of the DG-units. The worst case fault for a generator is a three phase fault. Therefore in every study case for all sections a dynamical simulation of a three phase short circuit is performed. The results of the study cases are presented in this section.

\section{A. Results of the case studies}

The case studies are performed with different protection settings. The protection settings for traditional and reduced grading are shown in table I. For Case 3 all the relays have the same pickup current and fault clearing time which are 1.4 p.u. and $0.1 \mathrm{~s}$.

TABLE I

RELAY SETTINGS FOR TRADITIONAL AND REDUCED GRADING

\begin{tabular}{|c|c|c|c|}
\hline \multirow{2}{*}{ Relay } & Pickup current & Traditional & Reduced \\
\cline { 2 - 4 } & $I>>$ [p.u.] & $t>>[\mathrm{s}]$ & $t>>[\mathrm{s}]$ \\
\hline$P r_{1 a}, P r_{5 b}$ & 1.4 & 1.2 & 0.5 \\
\hline$P r_{1 b}, P r_{5 a}$ & 1.4 & 0 & 0 \\
\hline$P r_{2 a}, P r_{4 b}$ & 1.4 & 0.9 & 0.375 \\
\hline$P r_{2 b}, P r_{4 a}$ & 1.4 & 0.3 & 0.125 \\
\hline$P r_{3 a}, P r_{3 b}$ & 1.4 & 0.6 & 0.250 \\
\hline
\end{tabular}

The simulations show that each protection scheme clears the fault in a correct way however, in case $\mathrm{C} 1$ and $\mathrm{C} 2$ all the clearing times exceeds the $\mathrm{CCT}$ of the generators. Hence in these cases the all 
generators are falling out of step. In the third case for all the simulated disturbances the fault clearing times are the same. The fault clearing time is set to $0.1 \mathrm{~s}$ which is within the CCT of the generators hence for each disturbance the generators stay in stable operation. The results of all the simulations are summarized in table II.

TABLE II

OVERVIEW OF SIMULATION RESULTS

\begin{tabular}{|c|c|c|c|c|c|c|}
\hline Feeder & \multicolumn{3}{|c|}{ Fault Clearing } & \multicolumn{3}{c|}{ Stable Operation } \\
\cline { 2 - 7 } No. & $C 1$ & $C 2$ & $C 3$ & $C 1$ & $C 2$ & $C 3$ \\
\hline Feeder 1 & Yes & Yes & Yes & No & No & Yes \\
\hline Feeder 2 & Yes & Yes & Yes & No & No & Yes \\
\hline Feeder 3 & Yes & Yes & Yes & No & No & Yes \\
\hline Feeder 4 & Yes & Yes & Yes & No & No & Yes \\
\hline Feeder 5 & Yes & Yes & Yes & No & No & Yes \\
\hline
\end{tabular}

In figure 7 for all cases the results of a short circuit at feeder 3 are depicted. When figure 7(a) and 7(b) are compared it can be concluded that in both cases the generators become unstable however, in case $\mathrm{C} 2$ the fault clearing time is slightly above the CCT of the generators which results in less pole slip. For all other simulated disturbances in case $\mathrm{C} 2$, the behavior of the generators are similar as in case $\mathrm{C} 1$ (see figure 7(a)). In figure 7(c) it is shown that after fault clearing all generators return to stable operation.

\section{B. Communication Delay}

In section VI the modeling of the directional relay including the delay of the communication process is discussed. The upstream blocking protection scheme is based on a blocking signal which is derived from the directional block in the relay. All directional elements are independent of each other hence each blocking signal is independent as well. To study the effect of the delay in the communication process it is sufficient to study the transfer of the blocking signals between two relays only. Transfer of blocking signals between all other relays in the test grid are exactly the same.

For proper operation of the upstream blocking protection scheme it have to be guaranteed that the blocking signal is present before the over-current block generates a trip signal otherwise unselective fault clearing will occur. The maximum allowable delay of the blocking signal can be determined with the aid of the following equation:

$$
t_{\text {delay }}<C C T-t_{C . B .}-t_{p, \text { dir }}
$$

where

$t_{\text {delay }}$ : Allowable delay time of blocking signal

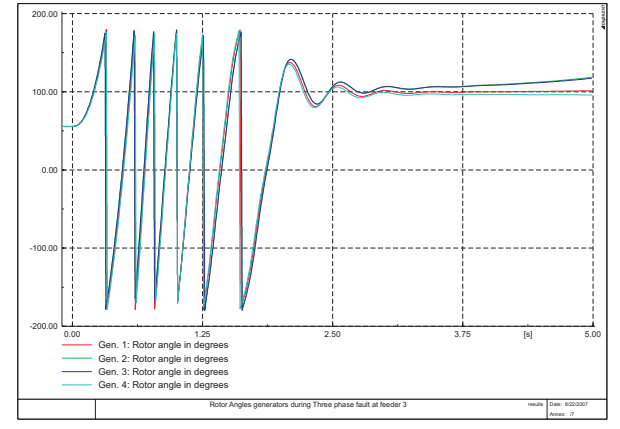

(a) Rotor Angles Case C1

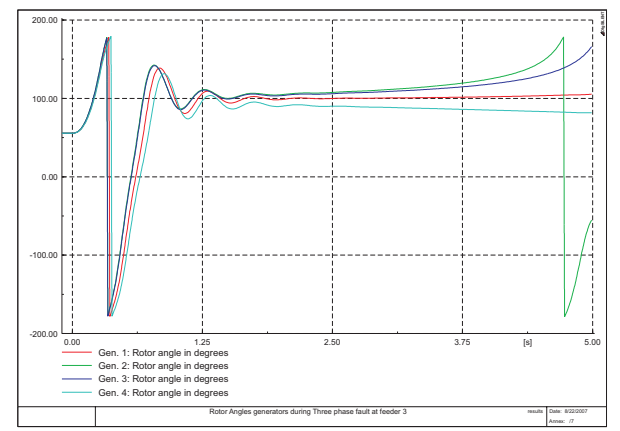

(b) Rotor Angles Case C2

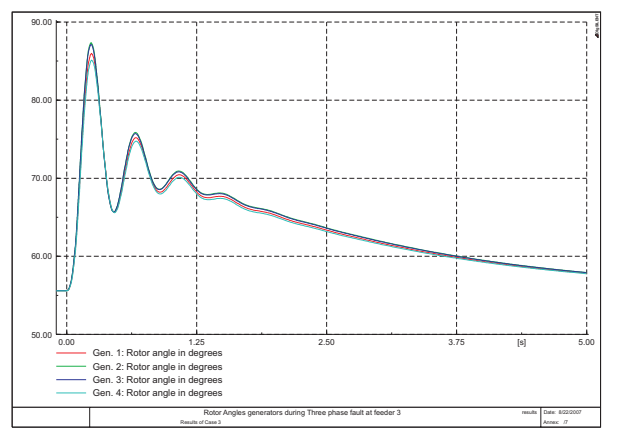

(c) Rotor Angles Case C3

Fig. 7. Results of the case studies for a three phase short circuit at feeder 3

$C C T$ : Critical Clearing Time of the generators $t_{C . B}$ : operating time of the circuit breaker $t_{p, \text { dir }}:$ pickup time of the directional block

In table III an overview of the pickup times of the various blocks and the maximum allowable delay time of the blocking signal are given. The maximum allowable delay time is $160 \mathrm{~ms}$. As mentioned earlier the CCT of the generators is 230 ms.

In figure 8 the timing components mentioned in (4) are depicted in a graphical way. A distinction is made between the timing components due to the internal processes of the relay and the operating 
TABLE III

ALLOWABLE DELAY TIME AND PICKUP TIMES OF OVER-CURRENT AND DIRECTIONAL BLOCK

\begin{tabular}{|c|c|c|c|}
\hline$t_{p, \text { dir }}[\mathrm{ms}]$ & $t_{C . B .}[\mathrm{ms}]$ & $t_{p, \text { ioc }}[\mathrm{ms}]$ & $t_{\text {delay }}[\mathrm{ms}]$ \\
\hline 20 & 50 & 20 & 160 \\
\hline
\end{tabular}

time defined by the user (delay time). In figure 8 also the pickup time of the over-current block $\left(t_{p, \text { ioc }}\right)$ and the user defined operating time $\left(t_{c l, i o c}\right)$ are shown. With the aid of this figure the maximal user defined operating time is:

$$
t_{c l, i o c}=C C T-t_{C . B .}-t_{p, i o c}
$$

where

$t_{c l, i o c}:$ Allowable user defined operating time $C C T$ : Critical Clearing Time of the generators $t_{C . B \text {. }}$ : Operating time of the circuit breaker $t_{p, i o c}$ : Pickup time of the over-current block

Due to the same values for $t_{p, i o c}$ and $t_{p, \text { dir }}$ the maximum user defined operating time is also 160 ms. Simulations have shown that after fault clearing the generators stay in stable operation when the calculated values for the user defined fault clearing time and the maximum delay time are applied.

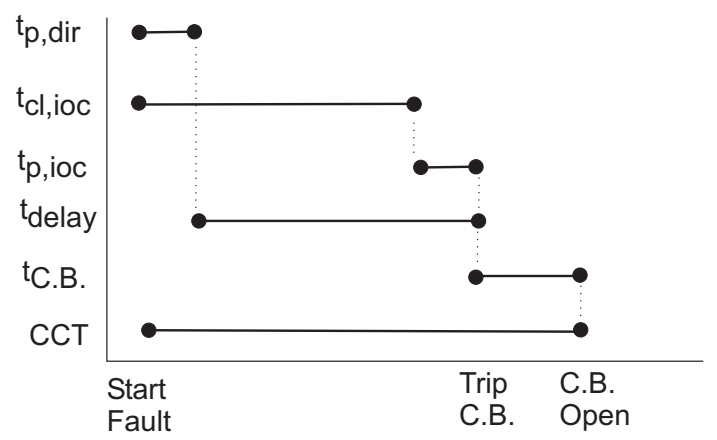

Fig. 8. Timing diagram communication process of the upstream protection scheme

The delay time of the communication process strongly depends on the applied communication channel. In [2] for optical fibre and wired communication channels a time delay of $10-30 \mathrm{~ms}$ is mentioned. These delays are sufficient small for a proper operation of the upstream protection system. Other communication channels can be applied as well if the delay time is within the upper limit of $160 \mathrm{~ms}$.

\section{Discussion AND CONClusions}

The increasing penetration level of DG-units can lead to requirements to prevent immediate disconnection of these units during and after a disturbance. These requirements can be met by changing the settings of the under-voltage protection. In this situation a consequence is that the over-current protection scheme have to be changed as well. In this paper it is shown that for MVring networks including DG-units the traditional graded directional over-current protection scheme clears the fault properly but do not guarantee stable operation of the DG-units. Reduction of the time grading reduces the duration of the voltage dip but still does not guarantee stable operation of the DGunits.

The fault clearing time can be further reduced by adding communication channels to the directional protection scheme. In this paper it is demonstrated by simulations that the addition of communication channels to the protection scheme results in a fault clearing time which is smaller than the CCT of the DG-units. This protection scheme makes it possible to clear the fault in a selective way and maintain stability of all the connected generators.

An attempt is made to calculate the maximum time delay of the communication process. The calculations are based on manufacturer's relay and circuit breaker data and the CCT of the DGunits. The maximum delay of the communication process is approximately $160 \mathrm{~ms}$ which can be reached easily by applying wired or optical fibre communication channels.

In existing grid situations the installation of communication channels is coupled with large investments. For protection issues only these costs can hardly justified in comparison with the benefits of improving the availability of the DG-units. However, in literature many advanced concepts and developments of active distribution grids are discussed which utilize communication channels [5], [6], [11]. The installation of communication channels can become attractive when the communication channel is shared by the various processes in the active distribution grid. Possible processes which can share the communication channel are operating and control signals from and to the dispatch center, data transfer of smart metering and, in the future, the control of virtual power plants. In this way new developments become possible which are hardly feasible when each individual development is justified by its own. 


\section{REFERENCES}

[1] 1547 ieee standard for interconnecting distributed resources with electrical power systems. IEEE, July, 2003.

[2] P.M. Anderson. Power System Protection. IEEE Press power engineering series. McGraw-Hill, New York, 1999.

[3] Pertti Järventausta Ari Nikander, Sami Repo. Utilizing the ring operation mode of medium voltage distribution feeders. In CIRED 17th International Conference on Electricity Distribution,May 12-15, Barcelona. 2003.

[4] W. Winter B.M. Buchholz, Z.A. Styczynski. Dynamic simulation of renewable energy sources and requirements on fault ride through behavior. In Power Engineering Society General Meeting, June 18-22, IEEE, 2006.

[5] Z.A. Styczynski B.M. Buchholz. Communication requirements and solutions for secure power system operation. In Power Engineering Society General Meeting, June 24-28, IEEE, 2007.

[6] Z.A. Styczynski B.M. Buchholz. New tasks create new solutions for communication in distribution systems. In Power Engineering Society General Meeting, June 18-22, IEEE, 2006.

[7] S. Lauria P. Masato F.M. Gatta, F Iliceto. Modeling and computer simulation of dispersed generation in distribution networks. measures to prevent disconnection during system disturbances. In IEEE Bologna PowerTech Conference, June 23-26, Bologna, Italy. IEEE, 2003.

[8] G. Pisano V. Allegranza R. Cicoria A. Iaria G. Celli, F. Pilo. Meshed vs. radial mv distribution network in presence of large amount of $\mathrm{dg}$. In Power Systems Conference and Exposition, October 10-13, IEEE, 2004.

[9] P. Kundur. Power system Stability and Control. McGraw Hill Inc., New York, USA, 1993.

[10] I.M. Rida S.K. Salman. Investigating the impact of embedded generation on relay settings of 'utilities' electrical feeders. In IEEE Transactions On Power Delivery, volume vol. 16, pages 246-251. 2001.

[11] Philipp Strauss Thomas Degner, Jürgen Schmid. Distributed generation with high penetration of distributed energy sources. Technical Report ENK-CT-2001-00522, DISPOWER, Kassel, Germany, 2006.

\section{BIOGRAPHIES}

Edward J. Coster (S' 06) was born in Leiden, The Netherlands, in 1972 . He received the B.eng degree in electrical engineering from TH Rijswijk in 1997 and the MSc. degree in electrical engineering from Delft University of Technology in 2000. From 2000 he is as a senior specialist for network planning with ENECO NetBeheer. In april 2006 he part-time joined the Electrical Power System group, Eindhoven University of Technology to start a PhD research project. His fields of interest are: Distributed Generation, Power System Protection, Dynamic Behavior and Stability of Power Systems.

Johanna M. A. Myrzik was born in Darmstadt, Germany in 1966. She received her MSc. in Electrical Engineering from the Darmstadt University of Technology, Germany in 1992. From 1993 to 1995 she worked as a researcher at the Institute for Solar Energy Supply Technology (ISET e.V.) in Kassel, Germany. In 1995 Mrs Myrzik joined the Kassel University, where she finished her $\mathrm{PhD}$ thesis in the field of solar inverter topologies in 2000. Since 2000, Mrs Myrzik is with the Eindhoven University of Technology, the Netherlands. In 2002, she became an assistant professor in the field of distributed generation. Her fields of interests are: power electronics, renewable energy, distributed generation, electrical power supply.

Wil L. Kling (M'95) was born in Heesch, the Netherlands in 1950. He received the MSc. degree in electrical engineering from the Technical University of Eindhoven, the Netherlands, in 1978. Fron 1978 to 1983 he worked with KEMA and from 1983 to 1998 with Sep. Since then he is with TenneT, the Dutch Transmission System Operator, as a senior engineer for network planning and network strategy. Since 1993 he is a parttime Professor at the Delft University of Technology and since 2000 he is also a part-time Professor in the Electrical Power Systems group at the Eindhoven University of Technology, the Netherlands. He is leading research programs on distributed generation, integration of wind power, network concepts and reliability. Mr. Kling is involved in scientific organizations such as Cigre and IEEE. He is the Dutch representative in the Cigre Study Committee C1 System Development and Economics 